\title{
IL8 polymorphisms and overall survival in pazopanib- or sunitinib-treated patients with renal cell carcinoma
}

C-F Xu*,1 ${ }^{*}$ T Johnson ${ }^{1}$, J Garcia-Donas ${ }^{2,3}, \mathrm{~T} \mathrm{~K} \mathrm{Choueiri}^{4}$, C N Sternberg ${ }^{5}$, I D Davis ${ }^{6}, \mathrm{~N} \mathrm{Bing}{ }^{7,12}, \mathrm{~K} \mathrm{C} \mathrm{Deen}^{8}$, Z Xue $^{7}, \mathrm{~L} \mathrm{McCann}^{8}$, E Esteban ${ }^{2,9}$, J C Whittaker ${ }^{1}, \mathrm{C}$ F Spraggs ${ }^{1}$, C Rodríguez-Antona ${ }^{10}$, L N Pandite ${ }^{7}$ and R J Motzer ${ }^{11}$

${ }^{1}$ GlaxoSmithKline, Gunnels Wood Road, Stevenage SG1 2NY, UK; ${ }^{2}$ Department of Medical Oncology, Centro Integral Oncológico Clara Campal, Calle de Oña 10, Madrid 28050, Spain; ${ }^{3}$ Spanish Oncology Genitourinary Group (SOGUG), Madrid, Spain; ${ }^{4}$ Department of Medical Oncology, Dana-Farber Cancer Institute, 450 Brookline Avenue, Boston, MA 02215, USA; ${ }^{5}$ Department of Medical Oncology, San Camillo and Forlanini Hospitals, Circonvallazione Gianicolense 87, Rome 00152, Italy; ${ }^{6}$ Monash University Eastern Health Clinical School, 5 Arnold Street, Victoria 3128, Australia; ${ }^{7}$ GlaxoSmithKline, 5 Moore Drive, Research Triangle Park, NC 27709, USA; ${ }^{8}$ GlaxoSmithKline, 250 S. Collegeville Road, Collegeville, PA 19426-0989, USA; ${ }^{9}$ Hospital Universitario Central de Asturias, Calle Carretera de Rubín, Oviedo 33011, Spain; ${ }^{10}$ Spanish National Cancer Research Centre and ISCIII Center for Biomedical Research on Rare Diseases (CIBERER), Calle de Melchor Fernández Almagro 3, Madrid 28029, Spain and ${ }^{11}$ Department of Medicine, Memorial Sloan-Kettering Cancer Center, 1275 York Avenue, New York, NY 10065, USA

Background: We evaluated germline single nucleotide polymorphisms (SNPs) for association with overall survival (OS) in pazopanib- or sunitinib-treated patients with advanced renal cell carcinoma (aRCC).

Methods: The discovery analysis tested 27 SNPs within 13 genes from a phase III pazopanib trial $(N=241$, study 1). Suggestive associations were then pursued in two independent datasets: a phase III trial (COMPARZ) comparing pazopanib vs sunitinib ( $N=729$, study 2) and an observational study of sunitinib-treated patients ( $N=89$, study 3$)$.

Results: In study 1, four SNPs showed nominally significant association ( $P \leq 0.05)$ with OS; two of these SNPs (rs1126647, rs4073) in IL8 were associated $(P \leq 0.05)$ with OS in study 2. Because rs1126647 and rs 4073 were highly correlated, only rs 1126647 was evaluated in study 3, which also showed association $(P \leq 0.05)$. In the combined data, rs1126647 was associated with OS after conservative multiple-test adjustment $\left(P=8.8 \times 10^{-5}\right.$; variant vs reference allele hazard ratio $1.32,95 \%$ confidence interval: $1.15-$ 1.52), without evidence for heterogeneity of effects between studies or between pazopanib- and sunitinib-treated patients.

Conclusions: Variant alleles of IL8 polymorphisms are associated with poorer survival outcomes in pazopanib- or sunitinib-treated patients with aRCC. These findings provide insight in aRCC prognosis and may advance our thinking in development of new therapies.

Renal cell carcinoma (RCC) is a heterogeneous collection of malignancies arising from the renal parenchyma, with $>200000$ new cases worldwide per year (Gupta et al, 2008; Escudier et al, 2013).
Although highly curable in its localised form by surgery, approximately a third of patients are diagnosed when metastatic spread has already occurred (Gupta et al, 2008); in addition,

*Correspondence: Dr C-F Xu; E-mail: chun-fang.2.xu@gsk.com

Previous Publication: Portions of the data were presented at the 2011 ASCO Genitourinary Cancers Symposium (abstract 303 ), the 2011 ASCO Annual Meeting (abstract 4558), and the 2013 ASCO Annual Meeting (abstract 4519).

${ }^{12}$ Currently affiliated with Pfizer, Inc., Boston, MA 02140, USA

Received 12 November 2014; revised 15 January 2015; accepted 27 January 2015;

published online 19 February 2015

(c) 2015 Cancer Research UK. All rights reserved 0007-0920/15

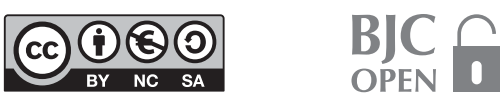


approximately $30 \%$ of patients surgically treated for a localised primary tumour will eventually develop metastases over time (Janowitz et al, 2013). The development of targeted systemic treatment options has improved clinical outcomes in patients with advanced and metastatic RCC (Molina and Motzer, 2011; Escudier et al, 2013; Fisher et al, 2013). Initial treatment decisions are based on prognosis of the disease using risk assessment models. Such prognostic models, initially developed for stratification of patients with metastatic RCC undergoing cytokine treatment (Motzer et al, 1999), have recently been extended to apply to patients receiving targeted therapies (Heng et al, 2009, 2013).

Pazopanib and sunitinib are angiogenesis inhibitors with highest affinity for vascular endothelial growth factor receptors, platelet-derived growth factor receptors, and stem cell factor receptor c-Kit (Motzer et al, 2007; Sternberg et al, 2010), and are approved for the treatment of advanced RCC. Treatment guidelines (Motzer et al, 2014; Escudier et al, 2014b) include both therapies as first-line options for RCC. Progression-free survival (PFS) benefits were observed for both sunitinib (vs interferon-alfa) and pazopanib ( $v s$ placebo) in their respective pivotal phase III studies (Motzer et al, 2007; Sternberg et al, 2010), but overall survival (OS) benefits were either marginal or not statistically significant (Motzer et al, 2007; Sternberg et al, 2013). However, these OS analyses were confounded by crossover or access to other therapies after progression. A recently completed phase III randomised clinical trial (COMPARZ) comparing pazopanib vs sunitinib for RCC demonstrated similar efficacies but differential safety profiles for the two therapies (Motzer et al, 2013), and a randomised cross-over phase III study (PISCES) demonstrated a significant patient preference for pazopanib over sunitinib with healthrelated quality of life and safety as key influencing factors (Escudier et al, 2014a).

There is substantial heterogeneity between patients with advanced RCC in prognosis and in response to treatment with targeted therapies, including pazopanib and sunitinib, and biomarkers that are predictive of clinical benefit would facilitate evidence-based selection of particular agents or dosages for optimal treatment of individual patients. The most obvious candidate biomarkers in clear-cell metastatic RCC (e.g., von Hippel-Lindau status, hypoxia-inducible factor (HIF) expression) have not been proven to have predictive significance (Fisher et al, 2013). As noted in recent reviews (Funakoshi et al, 2014; Maroto and Rini, 2014), some retrospective and prospective studies have reported potential molecular prognostic or predictive factors, including serum biomarkers (Tran et al, 2012; Harmon et al, 2014), tumour biomarkers (Rini et al, 2010; Dornbusch et al, 2013), and germline genetic variants (GarciaDonas et al, 2011; van der Veldt et al, 2011; Xu et al, 2011; Scartozzi et al, 2013). Specifically, genetic polymorphisms in genes involved in sunitinib pharmacokinetics (e.g., CYP3A5, NR1I3, and ABCB1) or mode of action (e.g., VEGFR3) have recently been reported to be associated with PFS or OS in advanced RCC (Garcia-Donas et al, 2011; Scartozzi et al, 2013). We have previously reported that genetic polymorphisms in IL8 and HIF1A may be associated with PFS, and polymorphisms in HIF1A, NR1I2, and VEGFA may be associated with best response (Xu et al, 2011). None of these genetic studies reported any attempt to confirm the association(s) in an independent dataset. To our knowledge, no prognostic or predictive biomarkers have yet to be prospectively validated in multiple independent studies to reliably distinguish patients with advanced RCC who are likely to respond from those who will not. To identify genetic predictors for OS, the present study used three independent datasets totalling 1059 pazopanib- or sunitinib-treated patients with advanced RCC.

\section{MATERIALS AND METHODS}

Patients. The discovery study (hereafter study 1) used data from participants in trials NCT00334282/VEG105192 and NCT00387764/VEG107769. The preplanned confirmation study (hereafter study 2) used data from participants in the COMPARZ trial: NCT00720941/VEG108844 and NCT01147822/VEG113078. Studies 1 and 2 included patients who provided written informed consent both for the clinical study and for genetic research. These clinical studies were conducted in accordance with the Declaration of Helsinki; protocols and informed consent forms were reviewed and approved by Institutional Review Boards and Independent Ethics Committees according to local guidelines. Post hoc, additional confirmation was sought using an observational study (hereafter study 3); the protocol was approved by the medical ethics review board of each participating institution and each participant provided written informed consent (Garcia-Donas et al, 2011).

Patient characteristics have been described previously (Sternberg et al, 2010; Garcia-Donas et al, 2011; Xu et al, 2011; Motzer et al, 2013) (Table 1). Briefly, NCT00334282 was a randomised, double-blind, placebo-controlled, pivotal phase III pazopanib study for advanced and/or metastatic RCC (Sternberg et al, 2010). NCT00387764 was an open-label extension to NCT00334282 providing the option for placebo-treated patients who developed progressive disease to receive pazopanib; OS for these patients was calculated from the time of initiation of pazopanib treatment in NCT00387764. Of the 369 patients enrolled in NCT00334282 and NCT00387764 who received pazopanib, study 1 used data from 241 patients who provided consent and a blood sample for genetic research. COMPARZ was a phase III randomised clinical trial comparing pazopanib vs sunitinib for metastatic RCC (Motzer et al, 2013). Of 1110 patients enrolled in COMPARZ, study 2 used data from 729 patients who received either pazopanib $(N=374)$ or sunitinib $(N=355)$ and provided consent and a blood sample for genetic research. Study 3 was an observational study undertaken by the Spanish Oncology GenitoUrinary Group (SOGUG); sunitinib-treated patients with clear-cell advanced RCC were included $(N=89)$. Compared with the analysis reported previously by Garcia-Donas (27 patients died, median follow-up 21.2 months) (Garcia-Donas et al, 2011), this analysis uses data from extended follow-up for OS (50 patients died, median follow-up 36.9 months).

Procedures. For studies 1 and 2, germline DNA was extracted from peripheral blood (QiAamp DNA Blood Kit; Qiagen, Valencia, CA, USA). In the discovery analysis, 27 potential functional single nucleotide polymorphisms (SNPs) were selected from 13 candidate genes with evidence of involvement in angiogenesis or in the metabolism, disposition, or mode of action of pazopanib (Xu et al, 2011). Genotyping was conducted using single-base chain extension assays modified by GlaxoSmithKline (Research Triangle Park, NC, USA), TaqMan SNP assays (Applied Biosystems, Foster City, CA, USA), GoldenGate and Infinium genotyping assays (Illumina, San Diego, CA, USA), the KASPar SNP genotyping system (LGC Genomics, Hoddesdon, UK), and Sanger sequencing. For study 3, DNA was isolated from peripheral blood with FlexiGene DNA kit (Qiagen) or from saliva with Oragene DNA self-collection kits (DNA Genotek, Ottawa, Canada), and genotyping was conducted using the KASPar SNP genotyping system (Garcia-Donas et al, 2011).

All genotypes were called following the assay manufacturers' guidelines. Genotyping quality was confirmed by call rate, manual examination of cluster plots, concordance with previously reported allele frequencies, and checks of Hardy-Weinberg proportions 
Table 1. Demographic and clinical characteristics of patients in the three studies

\begin{tabular}{|c|c|c|c|}
\hline Characteristics & $\begin{array}{c}\text { Discovery, Study } 1 \\
\text { (pazopanib) } N=241\end{array}$ & $\begin{array}{c}\text { Confirmation, Study } 2 \\
\text { (pazopanib or sunitinib) } \\
\qquad N=729\end{array}$ & $\begin{array}{c}\text { Confirmation, Study } 3 \\
\text { (sunitinib) } N=89\end{array}$ \\
\hline Age, median years (range) & $60(25-85)$ & $61(18-86)$ & $65(55-73)$ \\
\hline \multicolumn{4}{|l|}{ Sex, $n(\%)$} \\
\hline Male & $170(71)$ & $552(76)$ & $61(69)$ \\
\hline \multicolumn{4}{|l|}{ Race, self-reported, n (\%) } \\
\hline White & $209(87)$ & $453(62)$ & $87(98)$ \\
\hline Non-white & $32(13)$ & $276(38)$ & $2(2)$ \\
\hline Body mass index, median $\mathrm{kg} \mathrm{m}^{-2}$ (range) & $26(14-46)$ & $26(15-55)$ & NA \\
\hline \multicolumn{4}{|l|}{ ECOG PS or Karnofsky score, $n$ (\%) } \\
\hline ECOG 0/KS 90-100 & $93(39)$ & $556(76)$ & $23(28)$ \\
\hline ECOG 1/KS 70-80 & $144(60)$ & $167(23)$ & $53(64)$ \\
\hline ECOG $2 / \mathrm{KS} \leqslant 60 /$ missing $^{a}$ & $4(2)$ & $6(1)$ & $13(14)$ \\
\hline \multicolumn{4}{|l|}{ MSKCC risk score, $n$ (\%) } \\
\hline Favourable risk & $94(39)$ & $211(29)$ & $27(30)$ \\
\hline Intermediate risk & $130(54)$ & $420(58)$ & $44(49)$ \\
\hline Poor risk & $2(1)$ & $73(10)$ & $2(2)$ \\
\hline Unknown & $15(6)$ & $25(3)$ & $16(18)$ \\
\hline \multicolumn{4}{|l|}{ Time since initial diagnosis, $\boldsymbol{n}(\%)$} \\
\hline$\leqslant 1$ year & $74(31)$ & $400(55)$ & $47(53)$ \\
\hline$>1$ year & $139(58)$ & $329(45)$ & $42(47)$ \\
\hline Missing data & $28(12)$ & 0 & 0 \\
\hline \multicolumn{4}{|l|}{ Prior nephrectomy status, $n(\%)$} \\
\hline Yes & $216(90)$ & $611(84)$ & $76(85)$ \\
\hline No & $23(10)$ & $118(16)$ & $13(15)$ \\
\hline Missing data & $2(<1)$ & 0 & 0 \\
\hline \multicolumn{4}{|l|}{ LDH, $n(\%)$} \\
\hline$\leqslant 1 \cdot 5 \times$ ULN & $215(89)$ & $673(92)$ & $82(92)$ \\
\hline$>1.5 \times$ ULN & $16(7)$ & $45(6)$ & $4(4)$ \\
\hline Missing data & $10(4)$ & $11(2)$ & $3(3)$ \\
\hline \multicolumn{4}{|l|}{ Haemoglobin, $n$ (\%) } \\
\hline$\geqslant$ LLN & $129(54)$ & $445(61)$ & $55(62)$ \\
\hline$<\mathrm{LLN}$ & $104(43)$ & $284(39)$ & $33(37)$ \\
\hline Missing data & 8 (3) & 0 & $1(1)$ \\
\hline \multicolumn{4}{|l|}{ Prior systemic treatment, $n(\%)$} \\
\hline Treatment-naive & $128(53)$ & $729(100)$ & $89(100)$ \\
\hline Cytokine-pretreated & $105(44)$ & 0 & 0 \\
\hline Missing data & $8(3)$ & 0 & 0 \\
\hline \multicolumn{4}{|l|}{ Neutrophil count, $n$ (\%) } \\
\hline$\leqslant \mathrm{ULN}$ & $194(81)$ & $643(88)$ & 0 \\
\hline$>$ ULN & $39(16)$ & $82(11)$ & 0 \\
\hline Missing data & $8(3)$ & $4(1)$ & $89(100)$ \\
\hline \multicolumn{4}{|l|}{ Platelet count, $n(\%)$} \\
\hline$\leqslant \mathrm{ULN}$ & $184(76)$ & $629(86)$ & 0 \\
\hline$>$ ULN & $49(20)$ & $98(13)$ & 0 \\
\hline Missing data & $8(3)$ & $2(<1)$ & $89(100)$ \\
\hline PFS, median weeks $(95 \% \mathrm{Cl})$ & $38(28-52)$ & $48(38-49)$ & $55(33-77)$ \\
\hline OS, median months $(95 \% \mathrm{Cl})$ & $25(22-28)$ & $32(28-36)$ & $27(17-37)$ \\
\hline Tumour objective response, $\mathrm{n}(\%)^{\mathbf{b}}$ & $83(37)$ & $241(33)$ & $39(49)^{c}$ \\
\hline \multicolumn{4}{|c|}{$\begin{array}{l}\text { Abbreviations: } \mathrm{Cl}=\text { confidence interval; ECOG PS = Eastern Cooperative Oncology Group performance status; KS = Karnofsky score; LDH = lactate dehydrogenase; } L L N=\text { lower limit of normal } \\
\text { range; } \mathrm{MSKCC}=\text { Memorial Sloan-Kettering Cancer Center; OS = overall survival; PFS = progression-free survival; ULN=upper limit of normal range. } \\
\text { a One patient had missing baseline ECOG PS. All patients with ECOG PS of } 2 \text { or missing were from study VEG107769, had been randomised to the placebo arm of VEG105192, and later } \\
\text { experienced disease progression while on treatment or during the follow-up period. } \\
\text { bObjective response represents complete response and partial response. } \\
{ }^{\circ} \text { Nine had missing data, } 49 \%=39 \text { complete }+ \text { partial responses/80 patients with data. }\end{array}$} \\
\hline
\end{tabular}

within self-reported non-Hispanic white patients and within selfreported East Asian patients.

Statistical analysis. In study 1 (discovery analysis), following Motzer et al (1999, 2002) and Heng et al (2009), baseline factors were first individually evaluated for association with OS using a univariate Cox proportional hazards model, and subsequently evaluated using multivariate stepwise model selection (forward selection at $P \leq 0.1$ to enter the model and backward selection at $P \leq 0.05$ to stay in the model) (Table 2). Each SNP was tested for association with OS using a multivariate Cox model, assuming an additive genetic model, and adjusting for the baseline factors identified by the stepwise model selection. SNPs showing nominal significance $(P \leq 0.05$ without adjustment for the number of SNPs tested) were considered for evaluation in study 2 . 


\begin{tabular}{|c|c|c|c|c|}
\hline \multirow[b]{2}{*}{ Factors } & \multicolumn{2}{|c|}{ Univariate } & \multicolumn{2}{|c|}{ Multivariate $^{a}$} \\
\hline & HR (95\% Cl) & $P$ value & $\mathrm{HR}(95 \% \mathrm{Cl})$ & $P$ value \\
\hline Age, increase/year & $1.00(0.98-1.01)$ & 0.9 & - & - \\
\hline Sex, female vs male & $1.24(0.88-1.73)$ & 0.2 & - & - \\
\hline Race, self-reported other vs white & $0.92(0.57-1.48)$ & 0.7 & - & - \\
\hline BMI, per kg m ${ }^{-2}$ & $0.95(0.91-0.98)$ & 0.002 & $0.95(0.92-0.99)$ & 0.008 \\
\hline MSKCC risk score, intermediate/poor vs favourable & $1.93(1.37-2.73)$ & 0.0002 & - & - \\
\hline ECOG PS, 1 or 2 vs $0^{b}$ & $1.73(1.25-2.42)$ & 0.001 & $1.63(1.12-2.38)$ & 0.01 \\
\hline Haemoglobin, $<$ LLN vs $\geq$ LLN $^{\mathbf{b}}$ & $1.53(1.12-2.10)$ & 0.008 & - & - \\
\hline $\mathrm{LDH}_{,}>1.5 \times \mathrm{ULN}$ vs $\leq 1.5 \times \mathrm{ULN}^{\mathrm{b}}$ & $2.50(1.41-4.42)$ & 0.002 & - & - \\
\hline Prior nephrectomy status, no vs yes & $1.33(0.81-2.21)$ & 0.3 & - & - \\
\hline Prior systemic treatment, treatment-naive vs cytokine-pretreated & $1.24(0.90-1.71)$ & 0.2 & - & - \\
\hline Number of disease sites, $\geq 3$ vs 1 or 2 & $1.24(0.90-1.71)$ & 0.003 & $1.56(1.08-2.24)$ & 0.02 \\
\hline Time from initial diagnosis to study entry, $\leq 1$ year vs $>1$ year ${ }^{\mathbf{b}}$ & $1.81(1.29-2.54)$ & 0.0006 & $1.50(1.05-2.15)$ & 0.03 \\
\hline Neutrophil count, ULN vs $\leq$ ULN & $1.82(1.23-2.69)$ & 0.003 & $1.66(1.08-2.55)$ & 0.02 \\
\hline Platelet count, $>$ ULN vs $\leq$ ULN & $1.24(0.86-1.80)$ & 0.3 & - & - \\
\hline Study, VEG105192 vs VEG107769 & $1.06(0.72-1.56)$ & 0.8 & - & - \\
\hline \multicolumn{5}{|c|}{ 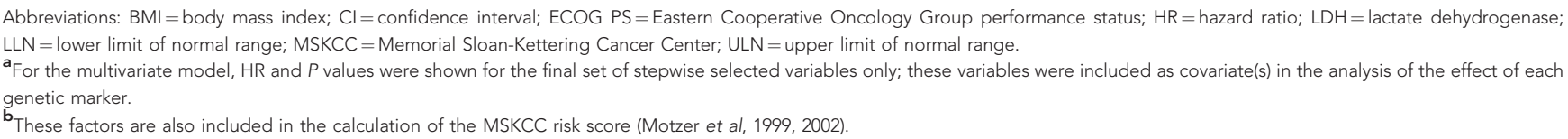 } \\
\hline
\end{tabular}

In studies 2 and 3 (preplanned and post hoc confirmation analyses, respectively), SNPs were tested for association with OS using a multivariate Cox model, assuming an additive genetic model. In study 2, analyses were adjusted for the same baseline covariates as in study 1, plus ancestry principal components to adjust for confounding by population structure (Price et al, 2006). In study 3 , analyses were adjusted for baseline Memorial Sloan-Kettering Cancer Center (MSKCC) risk score and sex, as described previously (Garcia-Donas et al, 2011). In parallel, SNPs nominally significantly associated $(P \leq 0.05)$ with either PFS or best response, as reported previously (Xu et al, 2011), were also tested for association with either PFS or best response in study 2. All analyses in study 2 were conducted separately in pazopanib-treated and in sunitinib-treated patients, and also in a combined analysis of all patients (with additional covariate adjustment for treatment). Two-tailed $P$ values were reported, and patients with missing baseline covariates or missing genotypes were excluded on a per-analysis basis.

Estimates of the natural-log hazard ratio (HR) from the multivariate Cox model analyses for study 1, from the two treatment arms of study 2 and from study 3, were combined using inverse variance weighted meta-analysis, assuming fixed effects and an additive genetic model. Heterogeneity of effects was assessed using the $\mathrm{I}^{2}$ index of heterogeneity and by Cochran's Q statistic. For meta-analysis, a conservative significance threshold was determined using Bonferroni correction for all discovery-only and discovery-plus-confirmation analyses that could have been conducted (27 SNPs $\times 4$ sequential analyses with increasing cumulative sample sizes; threshold $\left.0.05 / 27 / 4=4.6 \times 10^{-4}\right)$. Statistical analyses were conducted using the R system (Free Software Foundation, Boston, MA, USA), version 3.0.1.

\section{RESULTS}

We analyzed data from 1059 patients with advanced/metastatic RCC: 241 pazopanib-treated patients in study 1 (discovery); 374 pazopanib-treated and 355 sunitinib-treated patients in study 2 (preplanned confirmation); 89 sunitinib-treated patients in study 3 (post hoc confirmation). There was some heterogeneity in demographic and baseline clinical characteristics across the three datasets (Table 1). Similarly, there was a modest difference between studies in OS (Table 1); this likely reflects differences in baseline characteristics, as there was no significant difference in OS between pazopanib- and sunitinib-treated patients within study 2 (Motzer et al, 2013).

Table 2 lists the baseline factors evaluated in study 1 (discovery). Poor/intermediate MSKCC risk score, poor Eastern Cooperative Oncology Group (ECOG) performance status, low haemoglobin, high lactate dehydrogenase, high neutrophil count, increased number of disease sites, shorter time since initial diagnosis, and low body mass index were significantly associated with poor OS in univariate analyses. Multivariate stepwise model selection identified ECOG status, neutrophil count, number of disease sites, time since initial diagnosis, and body mass index as significantly associated with OS $(P \leq 0.05$, Table 2$)$. In analyses adjusted for these five baseline factors, five of the 27 SNPs studied were associated with OS at $P \leq 0.05$ in the discovery study 1 (Table 3 ). Although no single association was significant after adjusting for the 27 SNPs studied, the number of associations at $P \leq 0.05$ was higher than expected by chance, and therefore we hypothesised that some of these associations might be confirmed in a larger independent dataset. Excluding the SNP where only two patients carried the variant genotype, four SNPs were analyzed further.

We hypothesised that in patients with advanced RCC, genetic effects on OS could be similar for angiogenesis inhibitors in the same class (i.e., pazopanib and sunitinib). Therefore, for follow-up of the discovery findings, we tested the four SNPs in both the pazopanib and sunitinib arms of study 2 . In analysis of all patients in study 2, adjusted for treatment received, two IL8 SNPs were associated with $\mathrm{OS}$ at $P \leq 0.05$ (rs1126647, Figure 1A; rs4073, Supplementary Figure S1). Genotypes at these two IL8 SNPs were strongly correlated with each other (study $1 r^{2}=0.79 ; P<0.0001$ ), 
Table 3. Association between genetic markers and overall survival in pazopanib-treated patients in discovery study 1

\begin{tabular}{|c|c|c|c|c|c|}
\hline Gene & Polymorphism & rs Number & $\begin{array}{l}\text { Minor Allele } \\
\text { Frequency, \% }\end{array}$ & $P$ value $^{a}$ & $\mathrm{HR}^{\mathrm{a}}(95 \% \mathrm{Cl})$ \\
\hline CYP3A4 & $-392 A>G$ & rs2740574 & G 4.8 & 0.5 & $0.78(0.39-1.55)$ \\
\hline CYPЗА5 & $6986 \mathrm{~A}>\mathrm{G}$ & rs776746 & A 11.8 & 0.98 & $1.00(0.68-1.45)$ \\
\hline NR1/2 & $-25385 C>T$ & rs3814055 & T 39.0 & 0.02 & $1.34(1.04-1.73)$ \\
\hline NR1I2 & $7635 A>G$ & rs6785049 & G 40.6 & 0.7 & $0.96(0.74-1.24)$ \\
\hline NR1/2 & $10620 \mathrm{C}>\mathrm{T}$ & rs1054190 & Т 9.0 & 0.7 & $1.11(0.71-1.73)$ \\
\hline$A B C B 1$ & $1236 \mathrm{C}>\mathrm{T}$ & rs1128503 & T 43.2 & 0.054 & $1.25(1.00-1.58)$ \\
\hline$A B C B 1$ & $2677 \mathrm{G}>\mathrm{T} / \mathrm{A}(\mathrm{A} 893 \mathrm{~S} / \mathrm{T})$ & rs2032582 & T/A 45.4 & 0.3 & $1.14(0.89-1.47)$ \\
\hline$A B C B 1$ & $3435 C>T$ & rs1045642 & T 47.7 & 0.1 & $1.22(0.94-1.58)$ \\
\hline$A B C G 2$ & $34 \mathrm{G}>\mathrm{A}(\mathrm{V} 12 \mathrm{M})$ & rs2231137 & A 9.0 & 0.5 & $0.85(0.55-1.33)$ \\
\hline$A B C G 2$ & $421 \mathrm{C}>\mathrm{A}(\mathrm{Q} 141 \mathrm{~K})$ & rs2231142 & A 13.5 & 0.7 & $1.06(0.74-1.53)$ \\
\hline$A B C G 2$ & $869 \mathrm{C}>\mathrm{T}(\mathrm{Q} 126 \mathrm{X})$ & rs72552713 & T 0.4 & $0.03^{b}$ & $4.81(1.15-20.18)$ \\
\hline VEGFA & $-2578 A>C$ & rs699947 & C 47.9 & 0.2 & $0.85(0.66-1.09)$ \\
\hline VEGFA & $-1498 C>T$ & rs833061 & T 47.7 & 0.2 & $0.85(0.66-1.09)$ \\
\hline VEGFA & $-1154 \mathrm{G}>\mathrm{A}$ & rs1570360 & A 33.5 & 0.09 & $1.25(0.96-1.63)$ \\
\hline VEGFA & $-634 G>C$ & rs2010963 & C 27.8 & 0.2 & $0.83(0.62-1.11)$ \\
\hline VEGFA & $936 \mathrm{C}>\mathrm{T}$ & rs3025039 & T 15.3 & 0.4 & $1.15(0.82-1.62)$ \\
\hline VEGFR2 & $-604 \mathrm{~T}>\mathrm{C}$ & rs2071559 & C 43.5 & 0.4 & $0.90(0.70-1.14)$ \\
\hline VEGFR2 & $889 G$ > A (V297I) & rs2305948 & A 8.9 & 0.4 & $1.20(0.77-1.86)$ \\
\hline VEGFR2 & $1416 \mathrm{~A}>\mathrm{T}(\mathrm{Q} 472 \mathrm{H})$ & rs1870377 & T 22.6 & 0.3 & $0.86(0.64-1.16)$ \\
\hline VEGFR3 & 1480A $>\mathrm{G}(\mathrm{T} 494 \mathrm{~A})$ & rs 307826 & G 8.6 & 0.2 & $1.36(0.85-2.19)$ \\
\hline PDGFR $\alpha$ & $-573 G>T$ & rs1800812 & Т 21.7 & 0.3 & $0.86(0.66-1.13)$ \\
\hline IL8 & $2767 \mathrm{~A}>\mathrm{T}$ & rs1126647 & T 42.8 & 0.007 & $1.45(1.11-1.91)$ \\
\hline IL8 & $-251 \mathrm{~T}>\mathrm{A}$ & rs4073 & A 49.8 & 0.02 & $1.36(1.04-1.76)$ \\
\hline FGF2 & $224 \mathrm{C}>\mathrm{T}$ & rs1449683 & T 8.8 & 0.3 & $1.29(0.78-2.12)$ \\
\hline FGFR2 & IVS2 + 906C>T & rs2981582 & T 38.8 & 0.008 & 1.40 (1.09-1.81) \\
\hline$H I F 1 \alpha$ & $1772 \mathrm{C}>\mathrm{T}$ (P582S) & rs11549465 & T 10.3 & 0.6 & $0.88(0.58-1.34)$ \\
\hline$H I F 1 \alpha$ & $1790 \mathrm{G}>\mathrm{A}(\mathrm{A} 588 \mathrm{~T})$ & rs 11549467 & A 3.2 & 0.6 & $0.84(0.42-1.65)$ \\
\hline
\end{tabular}

with rs1126647 (IL8 2767A > T) showing stronger association in both study 1 and study 2 . Therefore, we focused on this SNP for a detailed description of the results. Given the inclusion of sunitinibtreated patients in study 2 but not in study 1, and a lack of other available genetic data for pazopanib-treated patients with advanced RCC, we sought additional confirmation for the association of rs1126647 in study 3.

In study 1 (pazopanib-treated, $N=241$ ), rs1126647 was significantly associated with $\mathrm{OS}(N=186 ; 125$ events; $P=0.007$, per allele $\mathrm{HR}=1.45,95 \%$ confidence interval (CI): 1.11-1.91; 18 patients had missing genotype data and 37 patients had missing data for baseline factors) (Table 3, Figure 2). The effect size estimate was similar when baseline factors were not adjusted for $(N=223 ; 148$ events; $P=0.003$, per allele $\mathrm{HR}=1.44,95 \% \mathrm{CI}$ : 1.13-1.83) (Figure 1A).

In study 2 (pazopanib- or sunitinib-treated, $N=729$ ), rs1126647 was significantly associated with OS $(N=690 ; 287$ events; $P=0.018, \mathrm{HR}=1.23,95 \% \mathrm{CI}: 1.04-1.46$, with adjustment for treatment; 10 patients had missing genotype data and 29 patients had missing data for baseline factors). The effect size estimate was similar when baseline factors were not adjusted for $(N=719 ; 299$ events; $P=0.014, \mathrm{HR}=1.24,95 \% \mathrm{CI}$ : 1.04-1.46) (Figure 1B). The HRs for association between rs1126647 and OS were not significantly different between pazopanib-treated patients
$(N=353 ; 146$ events; $P=0.53, \mathrm{HR}=1.08,95 \%$ CI: $0.84-1.40)$ and sunitinib-treated patients $(N=337 ; 141$ events; $P=0.008$, $\mathrm{HR}=1.39$, 95\% CI: 1.09-1.77) in study 2 (Figure 2), with overlapping CIs (Figure 3 ) and no significant genotype by treatment interaction effect $(P=0.23)$. The lack of a nominally significant association in pazopanib-treated patients in study 2 $(P=0.53)$ precludes straightforward interpretation of these results, which is an issue we discuss further.

In study 3 (sunitinib-treated, $N=89$ ), a significant association between rs1126647 and OS, with similar effect size, was observed $(N=88 ; 50$ events; $P=0.034, \mathrm{HR}=1.62,95 \% \mathrm{CI}: 1.04-2.54$; one patient had missing genotype data) (Figures $1 \mathrm{C}$ and 2).

Meta-analysis of results from all three studies showed overall a significant association between IL8 rs1126647 genotype and OS $\left(P=8.8 \times 10^{-5}, \mathrm{HR}=1.32\right.$ per $\mathrm{T}$ allele, $\left.95 \% \mathrm{CI}: 1.15-1.52\right)$ (Figure 2) that was significant after Bonferroni correction for all discovery-only and discovery-plus-confirmation analyses that could have been conducted using the available data (threshold $\left.P \leq 4.6 \times 10^{-4}\right)$. There was no significant heterogeneity in genetic effect size between studies ( $\mathrm{I}^{2}=19 \%$, Cochran's $\mathrm{Q}=3.73,3$ degrees of freedom, $P=0.29$ ).

Our previous pharmacogenetic analyses of pazopanib clinical trials for RCC (using data from study 1 plus an additional clinical trial that did not have OS data) suggested that three SNPs in the 

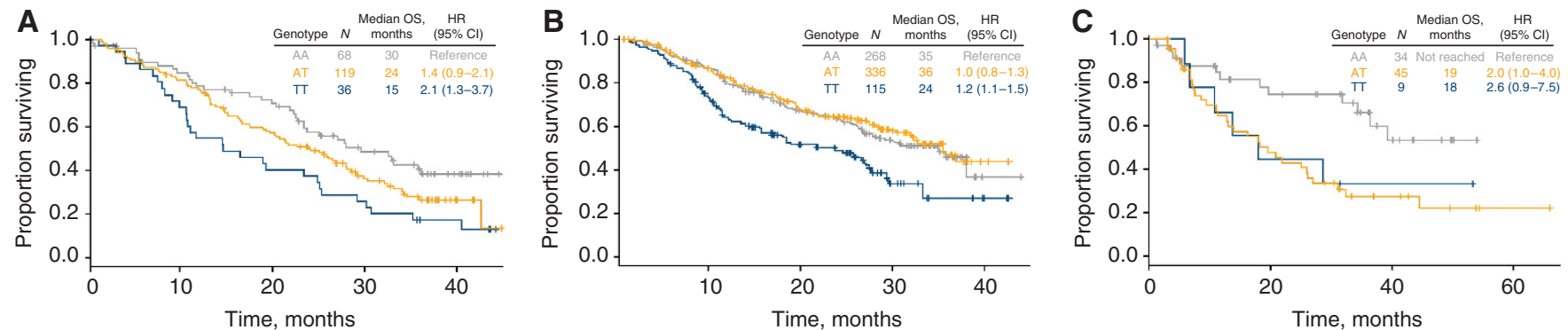

Figure 1. Overall survival Kaplan-Meier curves for patients by each IL8 2767A > T (rs1126647) genotype. (A) Pazopanib-treated patients in discovery study 1 (from NCT00334282 and NCT00387764): of the 241 patients, 223 had IL8 genotype data and were included in this plot (including the 37 patients who had missing data for baseline factors). The remaining 18 patients had missing genotype data. (B) Pazopanib- or sunitinib-treated patients in confirmation study 2 (from COMPARZ): of the 729 patients, 719 had IL8 genotype data and were included in this plot (including the 29 patients who had missing data for baseline factors). Ten patients had missing genotype data. (C) Sunitinib-treated patients in confirmation study 3 (SOGUG study): 88 of the 89 patients had IL8 genotype data and were included in this plot; one patient had missing genotype data. The curves show the proportion of patients in each genotype group who survived ( $y$ axis) vs time in months ( $x$ axis). Vertical bars on the survival curves indicate censored observations. The HR was adjusted for covariates comparing each of the variant genotype (AT or TT) with the reference genotype (AA). AA, reference genotype; $A T$, variant heterozygote genotype; TT, variant homozygote genotype.

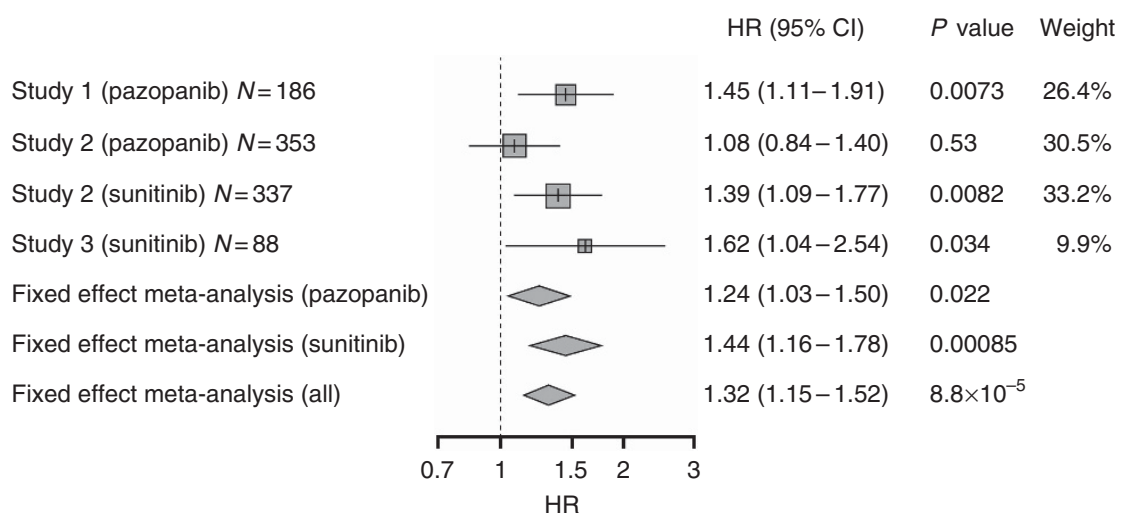

Figure 2. Forest plot of meta-analysis association results between IL8 rs1126647 polymorphism and OS across three independent studies (with confirmation study 2 split into pazopanib- and sunitinib-treated subgroups). The HR was per variant T allele compared with reference A allele using an additive genetic model.

IL8 and HIF1A genes may be associated with PFS, and that five SNPs in the HIF1A, NR1I2, and VEGFA genes may be associated with best response (Xu et al, 2011). None of these SNPs showed nominally significant association (at $P \leq 0.05$ ) with either PFS or best response in follow-up analyses in the subset of pazopanibtreated patients from study 2, but IL8 SNPs were weakly associated with PFS in sunitinib-treated patients.

\section{DISCUSSION}

Several antiangiogenesis agents are available for the treatment of advanced/metastatic RCC. However, few reliable predictors for treatment outcomes are available. The only externally validated models are the MSKCC or the International Metastatic Renal-Cell Carcinoma Database Consortium (IMDC) criteria that include baseline clinical factors to separate patients into risk categories with different prognoses (Motzer et al, 2002; Heng et al, 2013). Therefore, there is a growing interest in the field to explore pretreatment demographic and clinical factors, serum/tissue biomarkers, and germline genetic markers that are potentially associated with efficacy endpoints. Here, using data from 1059 patients in three independent datasets, we report that rs1126647 in IL8 is associated with OS in pazopanib- or sunitinib-treated patients with advanced RCC. Although the variant IL8 genotype (TT) was associated with shorter OS than other genotypes, all genotype subgroups had survival benefit from treatment with pazopanib or sunitinib. For example, the median OS was 21.4-23.7 months for patients with the variant TT genotype and 27.8-35.5 months for the other genotypes in COMPARZ (Figure 3), all of which were substantially improved compared with historical survival data in advanced RCC when cytokines were the mainstay treatment (median survival 13 months) (Motzer et al, 2000). As the magnitudes of OS benefit vary depending on IL8 genotypes, alternative sequencing or combination treatment strategies that are based on genotyping could be explored in the future as new therapies become available. Furthermore, the IL8 genotype data could be incorporated into a prognostic model such as the existing IMDC model to improve the predictions of patients' clinical outcomes (Heng et al, 2013).

Progression-free survival has been used as a primary endpoint in some oncology clinical trials and has been considered an acceptable surrogate for OS in some settings (Shea et al, 2013; Bria et al, 2015). We were able to demonstrate association of IL8 rs1126647 with OS but not with PFS. However, surrogacy with respect to the effect of a targeted therapy need not imply surrogacy with respect to effects of genetic differences, which may have distinct mechanism(s) of action (Fleming and DeMets, 1996). This raises the possibility that $I L 8$ variants may be associated with OS irrespective of treatment. 

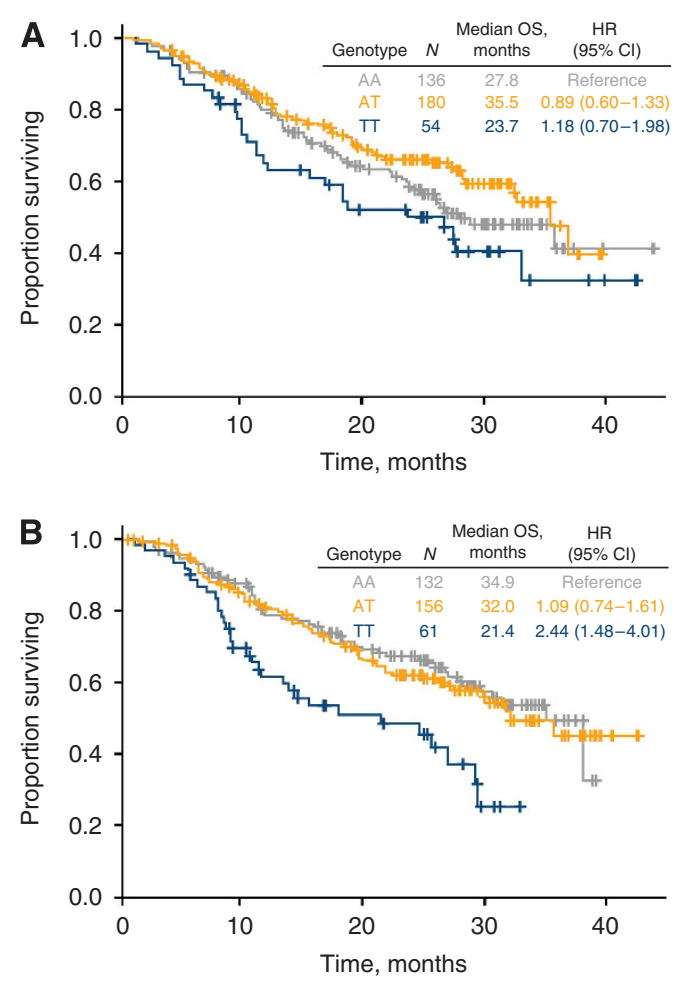

Figure 3. Overall survival (OS) Kaplan-Meier curves for IL8 2767A > T (rs1126647) genotype in confirmation study 2 (from COMPARZ) for (A) pazopanib-treated patients and (B) sunitinib-treated patients. Of the 729 patients, 719 had IL8 genotype data and were included in this plot (including the 29 patients who had missing data for baseline factors). Ten patients had missing genotype data. AA, reference genotype; AT, variant heterozygote genotype; TT, variant homozygote genotype.

As with many cancer therapies, the benefit of antiangiogenic therapy is often transient in the metastatic disease setting, and there has been an ongoing search to identify mechanisms of resistance. Although clinical examples of clearly established mechanisms of resistance to angiogenesis inhibitors remain limited, findings from cell culture and murine model studies have revealed that activation of alternate or redundant signalling pathways may represent one such mechanism (Mizukami et al, 2005; Huang et al, 2010). The IL8 protein possesses mitogenic and angiogenic properties (Koch et al, 1992), and IL8-mediated angiogenesis was identified as a key compensatory mechanism of resistance to sunitinib in murine models of RCC (Huang et al, 2010). The IL8 variant alleles evaluated in this study have been previously shown to be associated with increased gene expression (Hacking et al, 2004). Overexpression of IL8 is correlated with tumour stage, disease progression, and recurrence in various cancers (Yuan et al, 2005), as well as worse prognosis in localised RCC (Rini et al, 2010). In patients receiving pazopanib or sunitinib, high baseline serum IL8 levels were associated with shorter PFS and/or OS, suggesting that serum IL8 concentrations may be a prognostic or predictive factor for metastatic RCC (Liu et al, 2011; Tran et al, 2012; Harmon et al, 2014). One could therefore speculate that patients carrying the high-expression IL8 variants may have more aggressive tumours and thus reduced survival $v s$ those carrying the low-expression genotypes. It may be reasonable to consider IL8 blockade as a potential therapeutic target in future drug development for this patient subset.

Pharmacogenetic studies are often hampered by small sample sizes and limited availability of validation studies with eligibility criteria and treatment regimen similar to the discovery study. Strengths of the present study include a hypothesis-driven approach in a relatively large sample size study, the availability of one discovery and two confirmatory datasets, and detailed data on patient baseline characteristics. The prospective collection of germline DNA samples during pazopanib clinical trials enabled the evaluation of the effects of genetic markers on clinical response. Our evidence for association between OS and IL8 rs1126647 in pazopanib- and sunitinib-treated patients with RCC is based on a combined analysis of all data available for this study. Clearly, these data were accumulated in stages, and the inclusion of study 3 data in our analysis was post hoc. Nonetheless, the strength of association based on all available data $\left(P=8.8 \times 10^{-5}\right)$ remains significant after a conservative multiple testing correction that accounts for the number of stages of data accumulation and also for the total number of SNPs that could have been followed through these stages (threshold $P \leq 4.6 \times 10^{-4}$ ). The evidence for association of IL8 rs1126647 in patients treated with either pazopanib or sunitinib is supported by substantially overlapping 95\% CIs from treatment-specific meta-analyses (pazopanib 95\% CI: $1.03-1.50$, sunitinib 95\% CI: 1.16-1.78) (Figure 2). However, the association between OS and IL8 rs1126647 in patients with RCC requires bona fide prospective validation in further independent studies.

In conclusion, data from the present study suggest that variant alleles (associated with high expression) in the IL8 gene are associated with poorer survival outcome in patients with RCC who have received pazopanib or sunitinib. These findings provide additional scientific insight in the prognosis of advanced RCC after antiangiogenesis therapy, and may advance our thinking in developing new therapies.

\section{ACKNOWLEDGEMENTS}

This study was funded by GlaxoSmithKline. Pfizer provided funding for the Spanish Oncology Genitourinary Group (SOGUG) sunitinib study. We thank the investigators and their patients who made this study possible. We thank Karen King and Sandy Stinnett for their help in generation and management of the genetic data. We also thank Dr Enrique Grande for his support, and all members of SOGUG for their commitment to the project. Medical editorial assistance for the manuscript was provided by Joan Hudson and Jerome F. Sah, PhD, of ProEd Communications, Inc., Beachwood, Ohio, and was funded by GlaxoSmithKline, Philadelphia, Pennsylvania.

\section{CONFLICT OF INTEREST}

CFX, TJ, ZX, LM, JCW, CFS, and LNP are employees and stockholders of GlaxoSmithKline. NB and KCD were GlaxoSmithKline employees at the time of this study. JGD has received honoraria from GlaxoSmithKline, Pfizer, Novartis, and Bayer. CNS has received honoraria from GlaxoSmithKline, Pfizer, Novartis, and Bayer. IDD has been an advisory board member or chair for GlaxoSmithKline, Pfizer, Novartis, Janssen, Medivation, Sanofi, Bayer, Astellas, Ipsen, and Bristol-Myers Squibb, but all honoraria were directly donated to ANZUP Cancer Trials Group. TKC has received consultant compensation from GlaxoSmithKline, Pfizer, AVEO, Novartis, Genentech, Bayer, and Onyx. EE has been an advisory board member for GlaxoSmithKline, Pfizer, Novartis, and Bayer, but all honoraria were directly donated to UNDESO (foundation for the development of oncology research). RJM reports grants to his institution from GlaxoSmithKline, Pfizer, Novartis, and AVEO Oncology; he has received compensation from GlaxoSmithKline for travel and consultant compensation 
from Pfizer and Genentech. CR-A declares that she has no conflicts of interest.

\section{AUTHORS CONTRIBUTIONS}

CFX, JG-D, ZX, and CR-A contributed to study design and conduct, acquisition of data, and data interpretation. TJ and NB contributed to study design, statistical analysis, and data interpretation. TKC, CNS, IDD, and RJM contributed to study design, acquisition of clinical data and DNA samples, and data interpretation. KCD, LM, and LNP contributed to study design and data interpretation. EE contributed to acquisition of data and data interpretation. JCW and CFS contributed to data interpretation. All authors contributed to the writing of this report and approved the final version.

\section{REFERENCES}

Bria E, Massari F, Maines F, Pilotto S, Bonomi M, Porta C, Bracarda S, Heng D, Santini D, Sperduti I, Giannarelli D, Cognetti F, Tortora G, Milella M (2015) Progression-free survival as primary endpoint in randomized clinical trials of targeted agents for advanced renal cell carcinoma. Correlation with overall survival, benchmarking and power analysis. Crit Rev Oncol Hematol 93: 50-59.

Dornbusch J, Zacharis A, Meinhardt M, Erdmann K, Wolff I, Froehner M Wirth MP, Zastrow S, Fuessel S (2013) Analyses of potential predictive markers and survival data for a response to sunitinib in patients with metastatic renal cell carcinoma. PLoS One 8: e76386.

Escudier B, Albiges L, Sonpavde G (2013) Optimal management of metastatic renal cell carcinoma: current status. Drugs 73: 427-438.

Escudier B, Porta C, Bono P, Powles T, Eisen T, Sternberg CN, Gschwend JE, De Giorgi U, Parikh O, Hawkins R, Sevin E, Negrier S, Khan S, Diaz J, Redhu S, Mehmud F, Cella D (2014a) Randomized, controlled, doubleblind, cross-over trial assessing treatment preference for pazopanib versus sunitinib in patients with metastatic renal cell carcinoma: PISCES Study. J Clin Oncol 32: 1412-1418.

Escudier B, Porta C, Schmidinger M, Algaba F, Patard JJ, Khoo V, Eisen T, Horwich A. ESMO Guidelines Working Group (2014b) Renal cell carcinoma: ESMO Clinical Practice Guidelines for diagnosis, treatment and follow-up. Ann Oncol 25: iii49-iii56.

Fisher R, Gore M, Larkin J (2013) Current and future systemic treatments for renal cell carcinoma. Semin Cancer Biol 23: 38-45.

Fleming TR, DeMets DL (1996) Surrogate end points in clinical trials: are we being misled? Ann Intern Med 125: 605-613.

Funakoshi T, Lee CH, Hsieh JJ (2014) A systematic review of predictive and prognostic biomarkers for VEGF-targeted therapy in renal cell carcinoma. Cancer Treat Rev 40: 533-547.

Garcia-Donas J, Esteban E, Leandro-Garcia LJ, Castellano DE, Del Alba AG, Climent MA, Arranz JA, Gallardo E, Puente J, Bellmunt J, Mellado B, Martinez E, Moreno F, Font A, Robledo M, Rodriguez-Antona C (2011) Single nucleotide polymorphism associations with response and toxic effects in patients with advanced renal-cell carcinoma treated with firstline sunitinib: a multicentre, observational, prospective study. Lancet Oncol 12: 1143-1150.

Gupta K, Miller JD, Li JZ, Russell MW, Charbonneau C (2008) Epidemiologic and socioeconomic burden of metastatic renal cell carcinoma (mRCC): a literature review. Cancer Treat Rev 34: 193-205.

Hacking D, Knight JC, Rockett K, Brown H, Frampton J, Kwiatkowski DP, Hull J, Udalova IA (2004) Increased in vivo transcription of an IL-8 haplotype associated with respiratory syncytial virus disease-susceptibility. Genes Immun 5: 274-282.

Harmon CS, Deprimo SE, Figlin RA, Hudes GR, Hutson TE, Michaelson MD, Negrier S, Kim ST, Huang X, Williams JA, Eisen T, Motzer RJ (2014) Circulating proteins as potential biomarkers of sunitinib and interferon-alpha efficacy in treatment-naive patients with metastatic renal cell carcinoma. Cancer Chemother Pharmacol 73: $151-161$.

Heng DY, Xie W, Regan MM, Harshman LC, Bjarnason GA, Vaishampayan UN, Mackenzie M, Wood L, Donskov F, Tan MH, Rha SY, Agarwal N,
Kollmannsberger C, Rini BI, Choueiri TK (2013) External validation and comparison with other models of the International Metastatic Renal-Cell Carcinoma Database Consortium prognostic model: a population-based study. Lancet Oncol 14: 141-148.

Heng DY, Xie W, Regan MM, Warren MA, Golshayan AR, Sahi C, Eigl BJ, Ruether JD, Cheng T, North S, Venner P, Knox JJ, Chi KN, Kollmannsberger C, McDermott DF, Oh WK, Atkins MB, Bukowski RM, Rini BI, Choueiri TK (2009) Prognostic factors for overall survival in patients with metastatic renal cell carcinoma treated with vascular endothelial growth factor-targeted agents: results from a large, multicenter study. J Clin Oncol 27: 5794-5799.

Huang D, Ding Y, Zhou M, Rini BI, Petillo D, Qian CN, Kahnoski R, Futreal PA, Furge KA, Teh BT (2010) Interleukin-8 mediates resistance to antiangiogenic agent sunitinib in renal cell carcinoma. Cancer Res 70: 1063-1071.

Janowitz T, Welsh SJ, Zaki K, Mulders P, Eisen T (2013) Adjuvant therapy in renal cell carcinoma-past, present, and future. Semin Oncol 40: 482-491.

Koch AE, Polverini PJ, Kunkel SL, Harlow LA, DiPietro LA, Elner VM, Elner SG, Strieter RM (1992) Interleukin-8 as a macrophage-derived mediator of angiogenesis. Science 258: 1798-1801.

Liu Y, Tran HT, Lin Y, Martin AM, Zurita A, Sternberg CN, Team VEG, Amado R, Pandite LN, Heymach JV (2011) Baseline (BL) IL-6, IL-8, and VEGF as predictive and prognostic markers for overall survival (OS) in metastatic renal cell carcinoma (mRCC) patients (pts) treated in a phase III trial of pazopanib (PAZO) versus placebo (PL). Eur J Cancer 47: S170 Abstract 1404 (poster discussion).

Maroto P, Rini B (2014) Molecular biomarkers in advanced renal cell carcinoma. Clin Cancer Res 20: 2060-2071.

Mizukami Y, Jo WS, Duerr EM, Gala M, Li J, Zhang X, Zimmer MA, Iliopoulos O, Zukerberg LR, Kohgo Y, Lynch MP, Rueda BR, Chung DC (2005) Induction of interleukin-8 preserves the angiogenic response in HIF-1alpha-deficient colon cancer cells. Nat Med 11: 992-997.

Molina AM, Motzer RJ (2011) Clinical practice guidelines for the treatment of metastatic renal cell carcinoma: today and tomorrow. Oncologist 16: 45-50.

Motzer RJ, Bacik J, Murphy BA, Russo P, Mazumdar M (2002) Interferon-alfa as a comparative treatment for clinical trials of new therapies against advanced renal cell carcinoma. J Clin Oncol 20: 289-296.

Motzer RJ, Hutson TE, Cella D, Reeves J, Hawkins R, Guo J, Nathan P, Staehler M, de Souza P, Merchan JR, Boleti E, Fife K, Jin J, Jones R, Uemura H, De Giorgi U, Harmenberg U, Wang J, Sternberg CN, Deen K, McCann L, Hackshaw MD, Crescenzo R, Pandite LN, Choueiri TK (2013) Pazopanib versus sunitinib in metastatic renal-cell carcinoma. $N$ Engl J Med 369: 722-731.

Motzer RJ, Hutson TE, Tomczak P, Michaelson MD, Bukowski RM, Rixe O, Oudard S, Negrier S, Szczylik C, Kim ST, Chen I, Bycott PW, Baum CM, Figlin RA (2007) Sunitinib versus interferon alfa in metastatic renal-cell carcinoma. $N$ Engl J Med 356: 115-124.

Motzer RJ, Jonasch E, Agarwal N, Beard C, Bhayani S, Bolger GB, Chang SS, Choueiri TK, Derweesh IH, Gupta S, Hancock SL, Kim JJ, Kuzel TM, Lam ET, Lau C, Levine EG, Lin DW, Margolin KA, Michaelson MD, Olencki T, Pili R, Plimack ER, Rampersaud EN, Redman BG, Ryan CJ, Sheinfeld J, Sircar K, Somer B, Wang J, Wilder RB, Dwyer MA, Kumar R. National comprehensive cancer networks (2014) Kidney cancer, version 2.2014. J Natl Compr Canc Netw 12: 175-182.

Motzer RJ, Mazumdar M, Bacik J, Berg W, Amsterdam A, Ferrara J (1999) Survival and prognostic stratification of 670 patients with advanced renal cell carcinoma. J Clin Oncol 17: 2530-2540.

Motzer RJ, Mazumdar M, Bacik J, Russo P, Berg WJ, Metz EM (2000) Effect of cytokine therapy on survival for patients with advanced renal cell carcinoma. J Clin Oncol 18: 1928-1935.

Price AL, Patterson NJ, Plenge RM, Weinblatt ME, Shadick NA, Reich D (2006) Principal components analysis corrects for stratification in genome-wide association studies. Nat Genet 38: 904-909.

Rini BI, Zhou M, Aydin H, Elson P, Maddala T, Knezevic D, Parodi L, Bukowski RM, Novotny WF, Cowens JW (2010) Identification of prognostic genomic markers in patients with localized clear cell renal cell carcinoma (ccRCC). J Clin Oncol 28: 342s (Abstract 4501).

Scartozzi M, Bianconi M, Faloppi L, Loretelli C, Bittoni A, Del Prete M, Giampieri R, Maccaroni E, Nicoletti S, Burattini L, Minardi D, Muzzonigro G, Montironi R, Cascinu S (2013) VEGF and VEGFR polymorphisms affect clinical outcome in advanced renal cell carcinoma patients receiving first-line sunitinib. Br J Cancer 108: 1126-1132. 
Shea MB, Roberts SA, Walrath JC, Allen JD, Sigal EV (2013) Use of multiple endpoints and approval paths depicts a decade of FDA oncology drug approvals. Clin Cancer Res 19: 3722-3731.

Sternberg CN, Davis ID, Mardiak J, Szczylik C, Lee E, Wagstaff J, Barrios CH, Salman P, Gladkov OA, Kavina A, Zarba JJ, Chen M, McCann L, Pandite L, Roychowdhury DF, Hawkins RE (2010) Pazopanib in locally advanced or metastatic renal cell carcinoma: results of a randomized phase III trial. J Clin Oncol 28: 1061-1068.

Sternberg CN, Hawkins RE, Wagstaff J, Salman P, Mardiak J, Barrios CH, Zarba JJ, Gladkov OA, Lee E, Szczylik C, McCann L, Rubin SD, Chen M, Davis ID (2013) A randomised, double-blind phase III study of pazopanib in patients with advanced and/or metastatic renal cell carcinoma: final overall survival results and safety update. Eur J Cancer 49: 1287-1296.

Tran HT, Liu Y, Zurita AJ, Lin Y, Baker-Neblett KL, Martin AM, Figlin RA, Hutson TE, Sternberg CN, Amado RG, Pandite LN, Heymach JV (2012) Prognostic or predictive plasma cytokines and angiogenic factors for patients treated with pazopanib for metastatic renal-cell cancer: a retrospective analysis of phase 2 and phase 3 trials. Lancet Oncol 13: $827-837$.

Supplementary Information accompanies this paper on British Journal of Cancer website (http://www.nature.com/bjc) van der Veldt AA, Eechoute K, Gelderblom H, Gietema J, Guchelaar HJ, van Erp NP, van den Eertwegh AJ, Haanen JB, Mathijssen RH, Wessels JA (2011) Genetic polymorphisms associated with a prolonged progressionfree survival in patients with metastatic renal cell cancer treated with sunitinib. Clin Cancer Res 17: 620-629.

Xu CF, Bing NX, Ball HA, Rajagopalan D, Sternberg CN, Hutson TE, de Souza P, Xue ZG, McCann L, King KS, Ragone LJ, Whittaker JC, Spraggs CF, Cardon LR, Mooser VE, Pandite LN (2011) Pazopanib efficacy in renal cell carcinoma: evidence for predictive genetic markers in angiogenesis-related and exposure-related genes. J Clin Oncol 29: 2557-2564.

Yuan A, Chen JJ, Yao PL, Yang PC (2005) The role of interleukin-8 in cancer cells and microenvironment interaction. Front Biosci 10: 853-865.

(c) (1) (2) (2) This work is licensed under the Creative Commons Attribution-Non-Commercial-Share Alike 4.0 International License. To view a copy of this license, visit http:// creativecommons.org/licenses/by-nc-sa/4.0/

Supplementary Information accompanies this paper on British Journal of Cancer website (http://www.nature.com/bjc) 